Portland State University

PDXScholar

1973

\title{
Effects of Semantic Associational Strength and Verbal Sequence Length on the Auditory Comprehension of Aphasic Adults
}

Laurel J. Brown

Portland State University

Follow this and additional works at: https://pdxscholar.library.pdx.edu/open_access_etds

Part of the Speech Pathology and Audiology Commons Let us know how access to this document benefits you.

Recommended Citation

Brown, Laurel J., "Effects of Semantic Associational Strength and Verbal Sequence Length on the Auditory Comprehension of Aphasic Adults" (1973). Dissertations and Theses. Paper 1684.

https://doi.org/10.15760/etd.1682

This Thesis is brought to you for free and open access. It has been accepted for inclusion in Dissertations and Theses by an authorized administrator of PDXScholar. Please contact us if we can make this document more accessible: pdxscholar@pdx.edu. 
AN ABSTRACT OF THE THESIS OF Laurel J. Brown for the Master of Science in Speech Pathology and Audiology presented November 27, 1973.

Title: Effects of Semantic Associational Strength and Verbal Sequence Length on the Auditory Comprehension of Aphasic Adults.

APPROVED BY MEMBERS OF THE THESIS COMMITTEE:

Robert C. Marshall, Chairman

Joln McMahon

Robert I Castee1)

Keith Larson

The purpose of this study was to investigate the effects of semantic associational strength (SAS) upon adult aphasics' auditory comprehension abilities. Twenty-eight adult aphasics (25 males and 3 females) and 12 normal control subjects were presented three experimental tasks, each containing 45 items. Experimental task 1 contained single word picture sets of high SAS, moderate SAS, and low SAS words. Experimental task 2 contained two word picture sets of high, moderate, and low SAS words, and experimental task 3 contained three word picture sets of high, moderate, and low SAS words. Subjects heard one, two, 
and three word verbal sequences for experimental tasks 1, 2, and 3, respectively, and pointed to the appropriate picture sequence. Level of SAS was determined on the basis of the two most frequently occurring word associations of 50 normal individuals to 195 words selected from the most frequently occurring 3,000 English words.

The findings in this study revealed that aphasics had substantially more difficulty auditorily selecting picture sequences of high SAS words than sequences of moderate and low SAS words, and more difficulty auditorily selecting picture sequences of moderate SAS words than sequences of low SAS words. Results further indicated that, irrespective of degree of SAS between words, aphasics' retentional ability was adversely influenced by an increase in verbal sequence length. The presence of a significant interaction between the SAS and length factors negated the support for an interaction hypothesis that degree of SAS would differentially affect aphasics' comprehension as message length increased. Aphasics' performance on the experimental task was highly related to their overall communicative ability as assessed by the Porch Index of Communicative Ability. 
EFFECTS OF SEMANTIC ASSOCIATIONAL STRENGTH AND

VERBAL SEQUENCE LENGTH ON THE AUDITORY

COMPREHENSION OF APHASIC ADULTS

by

LAUREL J. BROWN

A thesis submitted in partial fulfillment of the requirements for the degree of

MASTER OF SCIENCE IN SPEECH:

EMPHASIS SPEECH PATHOLOGY AND AUDIOLOGY

Portland State University

1973 
TO THE OFFICE OF GRADUATE STUDIES AND RESEARCH:

The members of the Committee approve the thesis of Laurel $\mathrm{J}$. Brown presented November 27, 1973.

Robert C. Marshali, Chairman
Roph McMahon
Keith Larson L Caste81)

APPROVED:

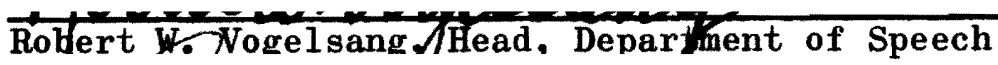

Dávid T. Clark, Dean of Graduate Studies and Research

Dec ember 10, 1973 


\section{ACKNOWLEDGMENTS}

It is a pleasure to express gratitude and appreciation to my chairman and director, Dr. Robert C. Marshall, for his time and efforts spent in the planning and completion of this study. Acknowledgment of their help and support is extended to the members of my committee, Joan McMahon, Dr. Robert Casteel, and Dr. Keith Larson. Fervent thanks are also expressed to Judy Rau and Mary $T$. Watts for their help in the collection of the data and to friends and fellow students who have given freely of their time and moral support when it was most needed.

Deep appreciation is expressed to my husband, Bill, for his immeasurable understanding and support through this period of graduate study and to my parents for their consistent encouragement. 
TABLE OF CONTENTS

PAGE

ACKNOWLEDGMENTS . • . . . . . . . . . . . . . .

LIST OF TABLES. . . . . . . . . . . . . . . . . v vi

LIST OF FIGURES . . . . . . . . . . . . . . . . . v vii

CHAPTER

I INTRODUCTION. .................. 1

II REVIEW OF THE LITERATURE. . . . . . . . . . . 5

Phonetic Discrimination in Aphasia. . . . . 7

Auditory Retention in Aphasia . . . . . . 8

Comprehension of Word Meaning in Aphasia. . . . 9

III METHODS AND PROCEDURES. . . . . . . . . . . 13

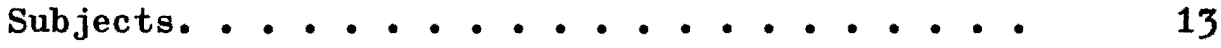

Procedure ................ 15

Stimulus Selection. . . . . . . . . . 19

Scoring of Responses. . . . . . . . . . 20

Scorer Reliability. . . . . . . . . . 22

IV RESULTS AND DISCUSSTON. . . . . . . . . . . 23

Results . . . . . . . . . . . . 23

Performance of Normal Control Subjects

Interscorer Reliability

Effects of SAS upon Auditory Comprehension

Effects of Sequence Length upon Auditory Retention

Effects of SAS upon Auditory Retention of

One, Two, and Three Word Sequences 
Relationship of Auditory Comprehension and Overall Language Ability

Discussion. . . . . . . . . . . . . . .

V SUMMARY AND CLINICAL IMPLICATIONS . . . . . . . . . 36

Summary . . . . . . . . . . . . . . 36

Clinical Implications . . . . . . . . . 38

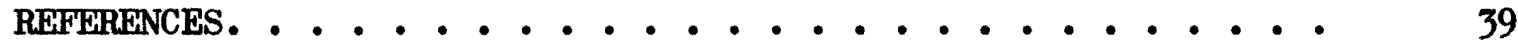

APPENDICES. . . . . . . . . . . . . . . . . . . . . . . . . . 43

Appendix A Association Task Given to 50 Normal Adults. Stimulus Order for Experimental Task 1. . 


\section{LIST OF TABLES}

TABLE

PAGE

I Description of aphasic subjects . . . . . . . . 14

II Stimuli selected for the experimental tasks . . . . . 21 


\section{LIST OF FIGURES}

1 Example of single word picture sequences . . . . 16

2 Example of two word picture sequences. . . . . . 17

3 Example of three word picture sequences. . . . . . 18

4 Aphasic subjects' means for low, moderate, and high SAS stimuli.....................

5 Aphasic subjects' means for one, two, and three word verbal sequences................

6 Aphasic subjects' means for low, moderate, and high SAS stimuli at three verbal sequence lengths .....

7 Regression line for aphasic subjects' grand means for the auditory tasks and overall PICA percentiles. . 


\section{CHAPTER I}

\section{INTRODUCTION}

A great deal of clinical and experimental investigation has centered on the identification and description of the language problems of aphasic adults. While there is general agreement that adult aphasia is a language deficit that results from brain damage, opinions vary as to whether aphasic adults simply manifest different degrees of aphasia or in fact illustrate different types of aphasia. Schuell et al. (1965) for example, defined aphasia as "a general language deficit that cuts across all language modalities that may or may not be complicated by other sequalae of brain damage." others, however (Weisenburg and McBride, 1935; Wepman et al., 1960; Geschwind, 1972), have categorized aphasic patients on the basis of the differences in their language behavior and, in some instances, have related these differences to areas of damage in the cortex. In spite of this controversy, the evaluation and treatment of the aphasic adult have continued to focus on describing and, whenever possible, improving the patient's functioning in the primary language modalities of speaking, writing, reading, and listening.

One area of particular interest to the aphasia clinician has been the auditory comprehension deficits that aphasic adults exhibit secondary to brain damage. Smith (1971) has pointed out that the severity of the patient's comprehension deficit in aphasia generally reflects the 
severity of the overall language impairment, and techniques designed to improve the aphasic's auditory comprehension skills form the foundation of many treatment programs. Schuell et al. (1965) felt all aphasics to have a reduced available vocabulary and a reduced verbal retention span. She suggested a highly auditory treatment approach for the aphasic based on intensive repetitive auditory stimulation.

There is good reason to believe that aphasic adults' ability to encode and decode verbal symbols varies inversely with the difficulty of the linguistic task. Porch (1967) has in fact defined aphasia as "a negative shift on the language response continuum" and most test batteries used to assess the aphasics' language functioning contain tasks of graduated difficulty so as to determine the level of functioning for the individual patient in each language mode (Eisenson, 1954; Wepman and Jones, 1961; DeRenzi and Vignolo, 1962; Schuell et al., 1962; Porch, 1967; Taylor, 1969; Spreen and Benton, 1969). With respect to the assessment of the auditory comprehension problems of the aphasic, attention has primarily focused on the patient's ability to discriminate, retain, and understand the meaning of verbal messages.

It has been clearly illustrated that aphasics have difficulty retaining messages of increasing length. This has been shown on tasks such as digit and sentence repetition, direction following, and pointing to items named serially. In each instance the result has been that when message length is increased the aphasic's retentional impairment becomes more obvious (Filby et al., 1963; Schuell et al., 1965; Shewan and Cantor, 1971). At the same time recent research suggests that aphasic patients also have considerable difficulty differentiating messages on 
the basis of their phonetic, structural, or semantic variation (Schuell et al., 1961; Schuell and Jenkins, 1961; Spinnler and Vignolo, 1962; Cohen and Edwards, 1964; Schuell et al., 1965; DeRenzi and Vignolo, 1966; Ebbin and Edwards, 1967; Parisi and Pizzamiglio, 1970; Pizzamiglio, 1971; Shewan and Cantor, 1971; Boller and Green, 1972; von Stockert, 1972; Carpenter and Rutherford, 1973). In other words, when the aphasic must do something as simple as to distinguish between phonemically varying words such as "cat" and "bat," syntactically varying structures such as "The girl drinks" and "The girl will drink," or semantically related words such as "pen" and "pencil," he may have considerable difficulty selecting the appropriate stimulus.

Two primary factors appear to have emerged from the literature with respect to the aphasic adult's comprehensional ability. One is that aphasics have difficulty understanding the meanings of words they hear and therefore tend to confuse words and structures related in meaning. The second is that they have difficulty retaining the words they hear for a sufficient length of time for them to be processed.

It is unfortunate that the effects of word relatedness and message length upon aphasics' comprehension have for the most part been investigated separately. Studies that have demonstrated that aphasics have difficulty distinguishing between semantically related words such as "hat" and "coat" (Schuell and Jenkins, 1961; Pizzamiglio, 1971) have employed single word stimuli. No attempts have been made to determine the effects of the semantic relationship between word stimuli in messages of increasing length. Furthermore, while it has been illustrated that aphasic adults tend to confuse words related in meaning (DeRenzi 
and Vignolo, 1963; Schuell et al., 1965; Boller and Green, 1972; Rinnert and Whitaker, 1973) the relationship between word stimuli has usually been implied rather than specified. It would seem reasonable that the more closely associated semantically word stimuli are, the more difficulty the aphasic will have distinguishing between them.

Accordingly, the purpose of this investigation is to determine the effects of semantic associational strength (SAS) upon the aphasic adult's auditory comprehension of three verbal sequence lengths. Specific research questions asked are as follows:

1. Does the degree of SAS between verbal stimuli influence aphasic adults' auditory comprehension ability?

2. Does verbal sequence length influence aphasic adults' auditory retention ability?

3. Does degree of SAS differentially influence aphasic adults' auditory retention of:

a. One word sequences?

b. Two word sequences?

c. Three word sequences?

4. Does a relationship exist between auditory comprehension ability and overall language ability? 
CHAPTER II

\section{REVIEW OF THE LITERATURE}

For several years clinical aphasiologists have studied the language behavior of aphasic adults and have attempted to quantify and qualify specific language deficits in this brain-injured population. Adult aphasia is generally considered a disturbance in language behavior, affecting all language modalities that may or may not be complicated by accompanying sensori-motor and/or perceptual deficits (Schuell et al., 1965). Several authors (Berry and Eisenson, 1956; Wepman et al., 1956; Schuell et al., 1961; 0sgood and Murray, 1963; Van Riper, 1963) have pointed out that aphasia is an impairment of symbolic formulation and expression and that aphasics have difficulty relating the symbol to the experience represented by that symbol. Schuell et al. (1965) have considered reduction of available vocabulary and reduced verbal retention span to be the two major problems of all aphasics.

In their text, "Aphasia in Adults," Schuell et al. (1965) suggested that all aphasic patients show demonstrable impairment of the auditory processes. They observed that even patients with mild aphasia show problems of auditory discrimination on tasks such as pointing to letters of the alphabet and reduced verbal retention span when asked to repeat digits and sentences, or to point to items named serially. According to Schuell, patients with moderate aphasia usually have further difficulty with rhyming or associating by sound. At more severe 
levels of impairment, Schuell has indicated that patients sometimes fail to recognize common words, confuse semantically associated words, have difficulty making phonemic discriminations, and have marked difficulty in responding to messages of increased length.

The importance of the auditory system in learning language and of the intensive stimulation of this system in reinstituting language in aphasics has been stressed by many investigators (Wepman, 1951; Schuell et al., 1961). Porch (1967), Schuell et al. (1965), and Brookshire (1972) have delineated several variables that may affect aphasics' auditory processing and have indicated that aphasics may fail to comprehend for a variety of reasons. Aphasics are felt to follow a pattern in the reacquisition of words similar to that seen in language acquisition of children. Wepman et al. (1956), Filby et al., (1963), Schuell et al., (1965) and others have stressed frequency of occurrence of words as an important factor in reestablishing language usage. Aphasics tend to reacquire vocabulary on the basis of the utility of the word, word length, and its frequency of occurrence. They tend to make fewer errors on common words of high immediate utility for all parts of speech. Many investigators (Filby et al., 1963; Sefer and Henrikson, 1966; Perry and Boswe11, 1971; Shewan and Cantor, 1971; Tikofsky, 1971) have compared the receptive vocabulary abilities of normals and aphasics on tasks requiring a non-verbal (pointing) response to a pictured representation of an auditorily presented stimulus and found the level of aphasics' performance to be well below that of the normal subjects. 
In summary, there is general agreement that all aphasics have some degree of auditory processing difficulty and that this ability is probably related to overall language ability (Schuell et al., 1965; Smith, 1971).

Phonetic Discrimination in Aphasia

A number of investigations have dealt with the ability of the aphasic adult to discriminate phonemes. Luria (1958) proposed that the breakdown in the understanding of speech in aphasia was affected by disintegration of the complex auditory function and produced an inability to utilize the systematized language code. He suggested that the aphasic loses phonemic analysis and may be unable to take in words and differentiate their meanings. Simultaneous synthesis, necessary for understanding, would therefore be impaired by the aphasic's inability to combine isolated elements into a single unit. More recently Luria (1970) pointed out that the aphasic's inability to discriminate perceived sounds can produce a profound impaiment of the entire auditory system.

Carpenter and Rutherford (1973) studied acoustic cue discrimination of aphasic adults and found that aphasics could not adequately discriminate the basic components of phonemes of which word-symbols are constructed. Similarly, Schuell (1953), Cohen and Edwards (1964), and Ebbin and Edwards (1967) have suggested that the aphasic's basic difficulty in deciphering language may be a deficit in discrimination of sounds and sound sequences, with impairment becoming more profound as length of the auditory pattern increases. 
Auditory Retention in Aphasia

In order to comprehend verbal material it is necessary to store (retain) the message for a sufficient period of time for it to be processed. Researchers have indicated that auditory retention span has a major influence upon comprehension. The ability of normal adults to understand messages has been shown to be influenced by sentence length (McMahon, 1963) and word difficulty (Nichols, 1965). Howes (1957) and Savin (1963) found that the frequency of occurrence of words influences comprehension. 0thers (Filby et al., 1963; Sefer and Henrikson, 1966; Swinney and Taylor, 1971; Perry and Boswell, 1971; Tikofsky, 1971) have found that aphasics performed more inferiorly than both children and normal adults in their ability to retain messages.

Shewan and Cantor (1971) specifically investigated the relationship between comprehension and message length. In their study, 27 aphasic and 9 normal adult subjects were given an auditory comprehension test consisting of 42 sentences which varied in the parameters of length, vocabulary difficulty, and syntactic complexity. They found that aphasic patients demonstrated poorer auditory comprehension than normal controls. Aphasics' mechanism for understanding language appeared to be much the same as normals; however, they seemed to employ this mechanism with reduced efficiency. This evidence parallels that of others (Filby et al., 1963; Sefer and Henrikson, 1966; Perry and Boswel1, 1971; Tikofsky, 1971) who have indicated that aphasics differentiate themselves from normals by their slower speed and frequently their lower levels of performance, but not by their inability to perform. 
Comprehension of Word Meaning in Aphasia

The ability to recognize meanings of words develops relatively early in childhood and represents one of the most stable language functions (Luria, 1958, 1970). Schuell and Jenkins (1961) have illustrated that aphasics have reduction of available vocabulary in all modalities. In this classic study, Schuell and Jenkins investigated reduction of vocabulary comprehension, reduction of naming vocabulary, reduction of reading vocabulary, and reduction of writing vocabulary in aphasia. Their experimental stimuli consisted of the test word, an object whose name rhymed with the test word, an object closely associated with the test object, and an unrelated object, i.e., "chair, stair, table, apple." The test word was spoken by the examiner and the subject was required to point to one of the four pictures on the stimulus card. They found that associational errors were the most common error type and constituted the greatest proportion of errors for patients with mild impairment. Confusion of words associated in meaning or experience was common to all modalities at all levels of impairment however. They also found an inverse relationship between association errors and total errors.

To investigate aphasics' ability to recognize meaningful sounds, Spinnler and Vignolo (1966) administered a sound recognition test to normal subjects, subjects with cerebral lesions without aphasia, and subjects with cerebral lesion with aphasia. They presented ten familiar and meaningful sounds over a tape recorder. After listening to the sound the subjects indicated (by pointing) which of the four pictures represented the sound. The four picture choices consisted of (1) the 
natural source of the sound, such as "the grunting of a pig," (2) a sound acoustically similar, such as "a capstan pulling an anchor," (3) a sound belonging to the same semantic category, such as "a sheep bleating," and (4) a sound with no relationship, such as "a man whistling." Errors were then classified as acoustic errors, semantic errors, or odd errors. Their findings indicated that a sound recognition deficit in aphasics was associated with problems of auditory verbal comprehension. The performance of the aphasic group differed from that of the other groups with respect to type of error in that they made significantly more semantic than acoustic or odd (unrelated) errors. Similar to Schuell's data, these findings strongly suggested that aphasics' failure to recognize meaningful sounds is not due to an acoustic-perceptual impairment as much as it is their inability to associate the perceived sound with its correct meaning.

Schuell and Jenkins (1961) have reported that the error responses of aphasics are similar to free association responses given by normals. There are also other indications that simple associative processes play an important part in many aspects of normal language behavior. Rinnert and Whitaker (1973) compared word pairs confused by aphasics with various tables of word association norms and found that these confusions were by no means random substitutions but could be categorized on the basis of their semantic association. Cramer (1968) has conducted numerous word association investigations with subjects having various types of organically based pathologies. His findings support reports of severe restriction in the number of associative pathways which can 
be activated by a stimulus in a brain-injured adult. He concluded that the brain-damaged have a marked reduction in the number of responses available to any one stimulus.

Some investigators have attempted to study the auditory associational responses of aphasics. Pizzamiglio (1971) constructed a test to measure the ability of aphasics to understand the exact meaning of the words perceived. A multiple choice test with words grouped into clusters of four words with a high associative overlapping was presented to sixty aphasic and thirty normal subjects. The stimulus word presented in each case was the word with the highest associative overlapping and this was taken as an index of the semantic similarity between words. Four picture-sets containing stimuli such as "hand, foot, leg, finger" were presented visually and subjects were required to point to the appropriate stimulus word presented auditorily. Aphasics were found to confuse words that had a high degree of associational overlap and made significantly lower scores than the normal subjects. Schuell et al. (1961) have reported that aphasics tend to auditorily confuse words related in meaning or experience. Boller and Green (1972) have also proposed that for detailed comprehension, the aphasic must attend more closely to the semantic properties of the words and their intimate structural relations.

In summary, aphasics have been found to demonstrate problems of phonemic discrimination, auditory retention, and vocabulary comprehension. Semantic or associational confusions appear to be observed with all aphasics regardless of level of impairment and it would appear that the more closely associated in meaning two words are, the more difficulty 
the aphasic is likely to have understanding them. Unfortunately, no attempts have been made to determine the effect of degree of associational strength on aphasics' comprehension performance. If the degree of association between words does adversely influence comprehension, one might expect this problem to be manifest regardless of the length of the message.

It is the purpose of this study to determine the effects of semantic associational strength and length of message upon the auditory comprehension of aphasic adults. 


\section{CHAPTER III}

\section{METHODS AND PROCEDURES}

\section{Subjects}

Subjects for this study were 28 aphasic adults (25 males and 3 females) and 12 normal adult controls. All aphasic subjects were (1) diagnosed as aphasic by an experienced speech pathologist, (2) currently receiving or had previously received speech therapy, (3) between 25 and 75 years of age, with a mean of 51 years, (4) aphasic as the result of cerebral vascular accident (CVA), (5) had suffered no more than one medically documented CVA, and (5) at least three months post CVA. Severity of aphasia for the 28 subjects was determined on the basis of subjects' percentile rankings on the Porch Index of Communicative Ability (PICA) (Porch, 1967). Only aphasics who fell between the 25th and 95th percentiles on the PICA were used as subjects. The aphasic subjects are further described in Table $I$.

Twelve normal adults ( 6 males and 6 females) were selected as control subjects. These subjects were considered to have normal language abilities as judged by the experimenter from their conversational speech and reported no previous or present history of neurological involvement. The control group was comparable with the aphasic group in terms of chronological age. Their ages ranged from 26 to 67 years, with a mean of 47 years. 
TABLE I

DESCRIPTION OF APHASIC SUBJECTS

\begin{tabular}{|c|c|c|c|c|}
\hline $\begin{array}{c}\text { SUBJECT \# } \\
1\end{array}$ & $\begin{array}{c}\text { SEX } \\
M\end{array}$ & $\begin{array}{l}\text { AGE } \\
47\end{array}$ & $\begin{array}{c}\text { MONTHS POST } \\
\text { ONSET } \\
24\end{array}$ & $\begin{array}{c}\text { PICA } \not b \text {-ile } \\
76\end{array}$ \\
\hline 2 & M & 55 & 14 & 75 \\
\hline 3 & $\mathbf{M}$ & 68 & 15 & 50 \\
\hline 4 & M & 43 & 36 & 64 \\
\hline 5 & $\mathbf{M}$ & 48 & 18 & 50 \\
\hline 6 & $\mathbf{M}$ & 41 & 27 & 70 \\
\hline 7 & M & 53 & 50 & 78 \\
\hline 8 & $M$ & 57 & 45 & 50 \\
\hline 9 & $\mathbf{F}$ & 41 & 43 & 95 \\
\hline 10 & F & 44 & 59 & 77 \\
\hline 11 & M & 74 & 12 & 64 \\
\hline 12 & M & 56 & 27 & 45 \\
\hline 13 & M & 55 & 156 & 50 \\
\hline 14 & M & 70 & 74 & 37 \\
\hline 15 & M & 57 & 15 & 71 \\
\hline 16 & M & 39 & 7 & 74 \\
\hline 17 & M & 25 & 21 & 89 \\
\hline 18 & M & 56 & 7 & 59 \\
\hline 19 & M & 38 & 67 & 46 \\
\hline 20 & M & 48 & 71 & 41 \\
\hline 21 & M & 53 & 66 & 52 \\
\hline 22 & M & 55 & 7 & 88 \\
\hline 23 & M & 49 & 76 & 55 \\
\hline 24 & M & 49 & 24 & 94 \\
\hline 25 & M & 60 & 156 & 78 \\
\hline 26 & M & 58 & 15 & 75 \\
\hline 27 & $F$ & 47 & 18 & 49 \\
\hline 28 & M & 50 & 4 & 46 \\
\hline
\end{tabular}


Procedure

Three experimental tasks, each containing 45 items, were administered to the subjects. In each task, subjects selected (by pointing) a picture or sequence of pictures in response to an auditory stimulus. In experimental task 1 (Figure 1) the subjects viewed three pictures, heard one stimulus word, and pointed to the appropriate picture. In experimental task 2 (Figure 2) subjects viewed three two-picture sequences, heard two stimulus words corresponding to one of the sequences, and pointed to the appropriate picture sequence. In experimental task 3 (Figure 3) subjects were presented three three-picture sequences, heard three stimulus words corresponding to one of the sequences, and pointed to the appropriate sequence of pictures. Figures 1, 2, and 3 also illustrate the means by which the same stimuli (pictures) were employed in all three experimental tasks and that each picture or picture sequence was presented as the stimulus on one occasion.

As in Figures 1, 2, and 3, all pictures and picture sequences were pictorially displayed with $2 " \times 2 "$ black and white drawings on $8 \frac{1}{2} " \times 11^{\prime \prime}$ white cards. A strip of magnetic recording tape was affixed to the base of each card and a Standard American speaking male recorded the appropriate word or word sequence for each card over the recording system of an Electronic Card Reader (ECR). This allowed all subjects to hear the same stimulus presentations. All stimuli were presented individually over the playback system of the ECR unit.

During administration of the three tasks the subject and the experimenter sat at a large table in a quiet room facing the ECR unit and a loudspeaker through which all stimuli were played. Stimuli were 


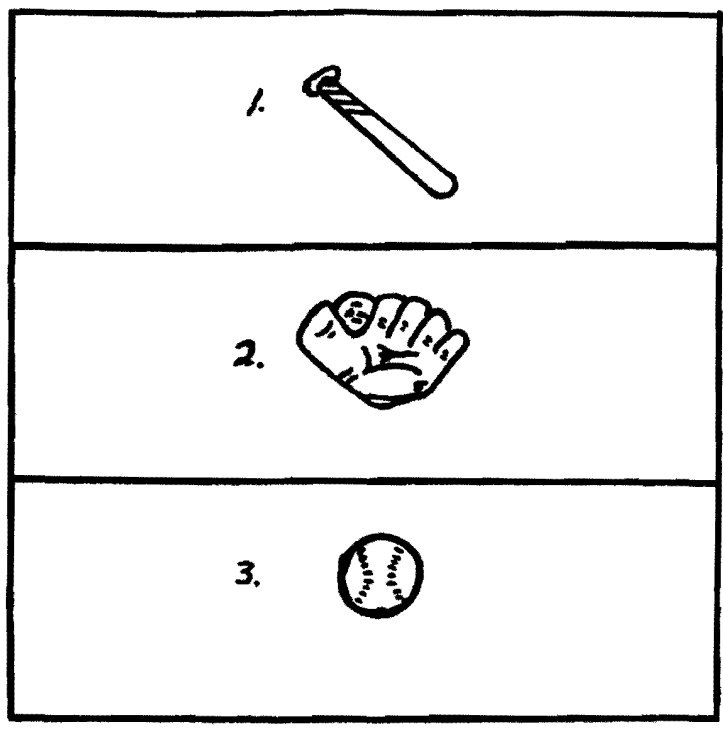

Stimulus: BALL
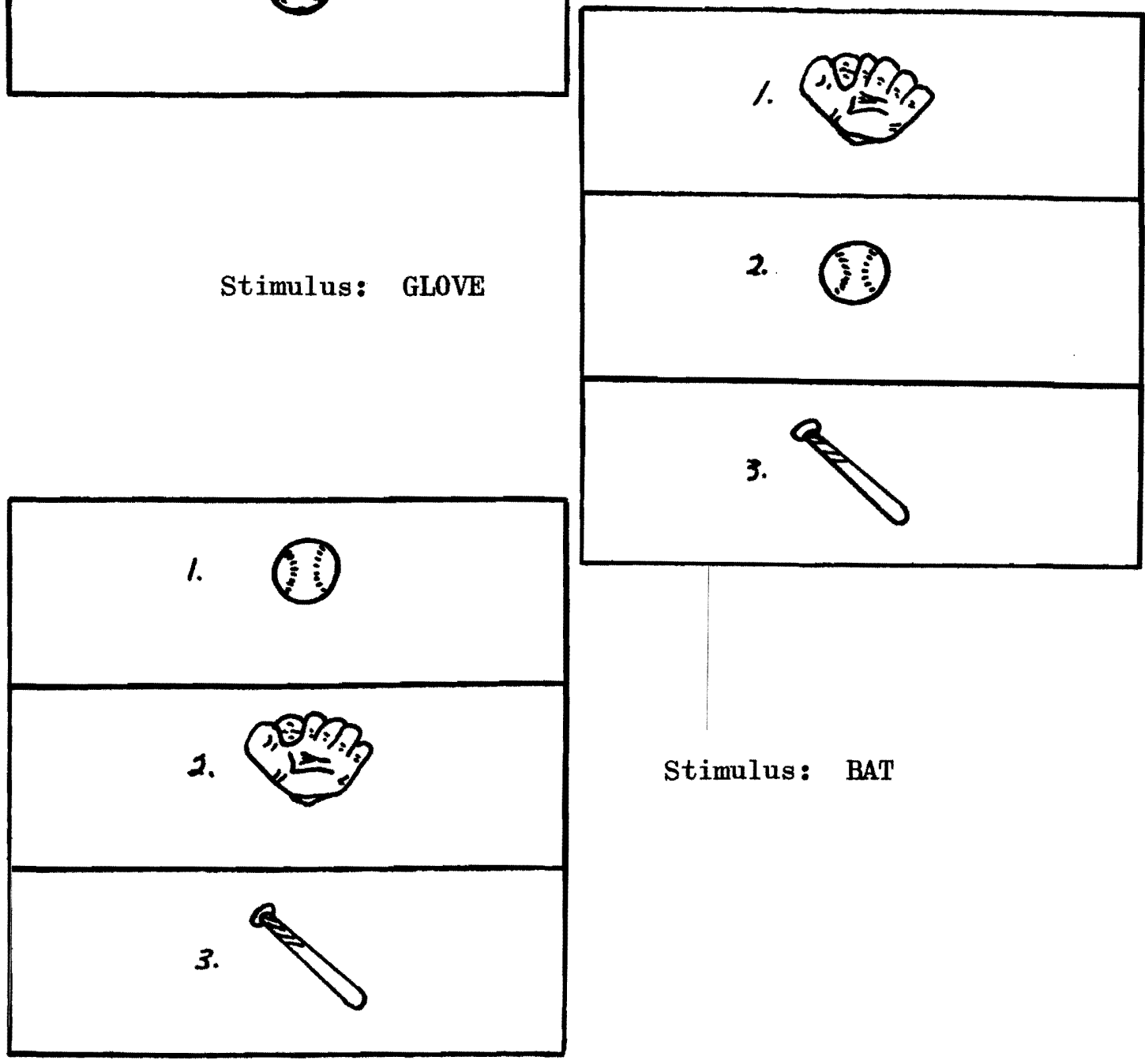

Stimulus: BAT

Figure 1. Example of single word picture sequences. 

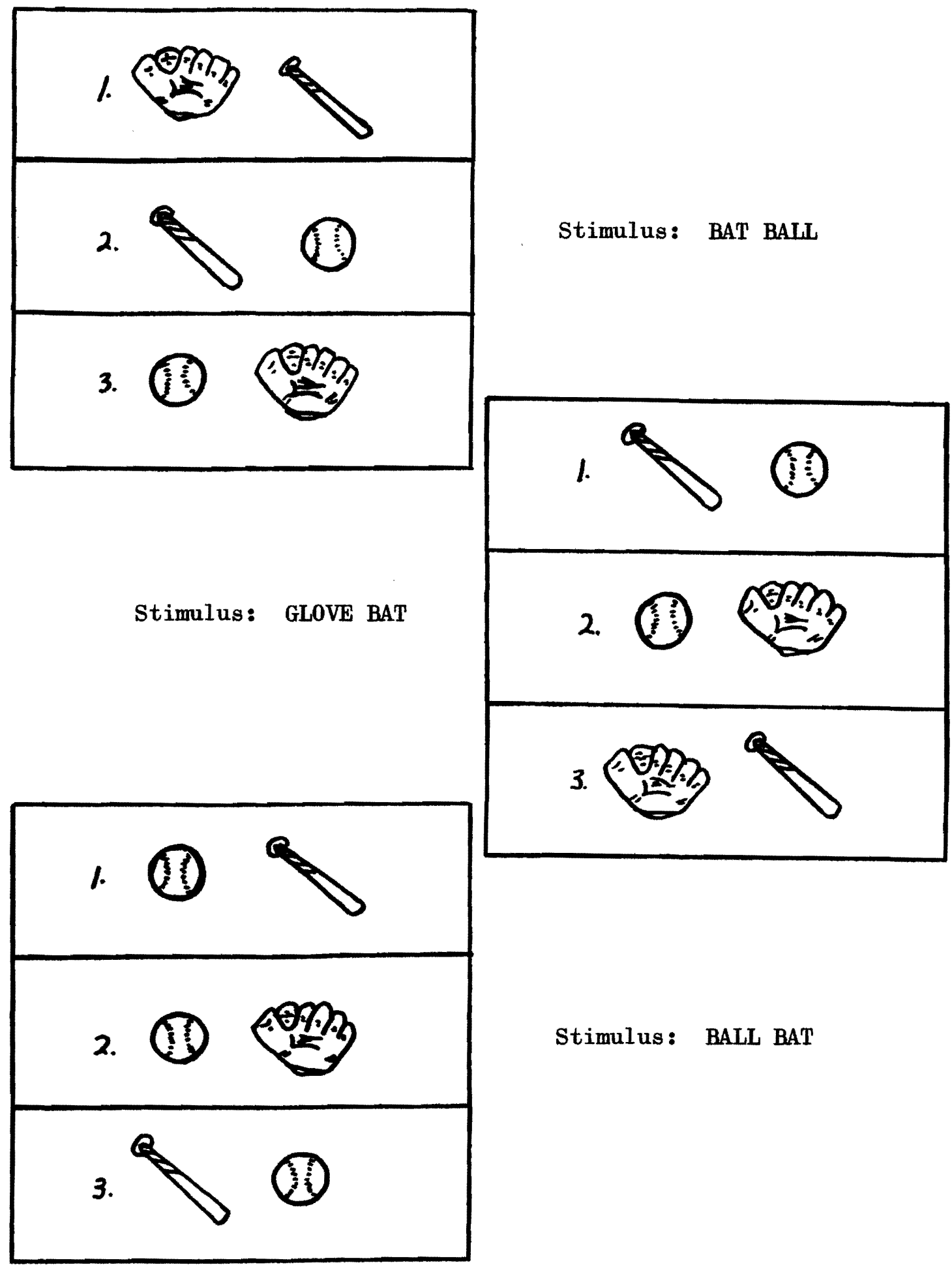

Stimulus: BAT BALL

Stimulus: GLOVE BAT

Figure 2. Example of two word picture sequences. 


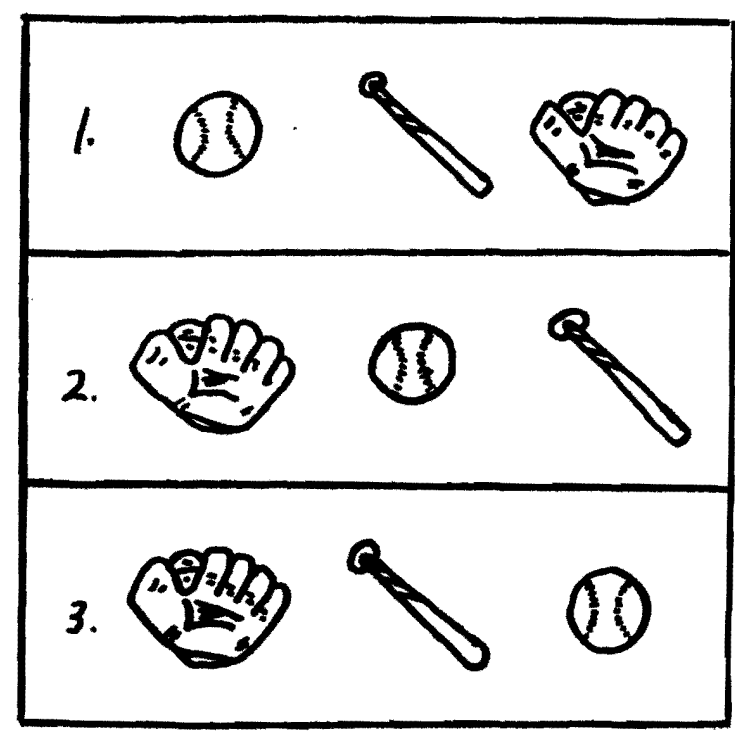

Stimulus: GLOVE BALL BAT
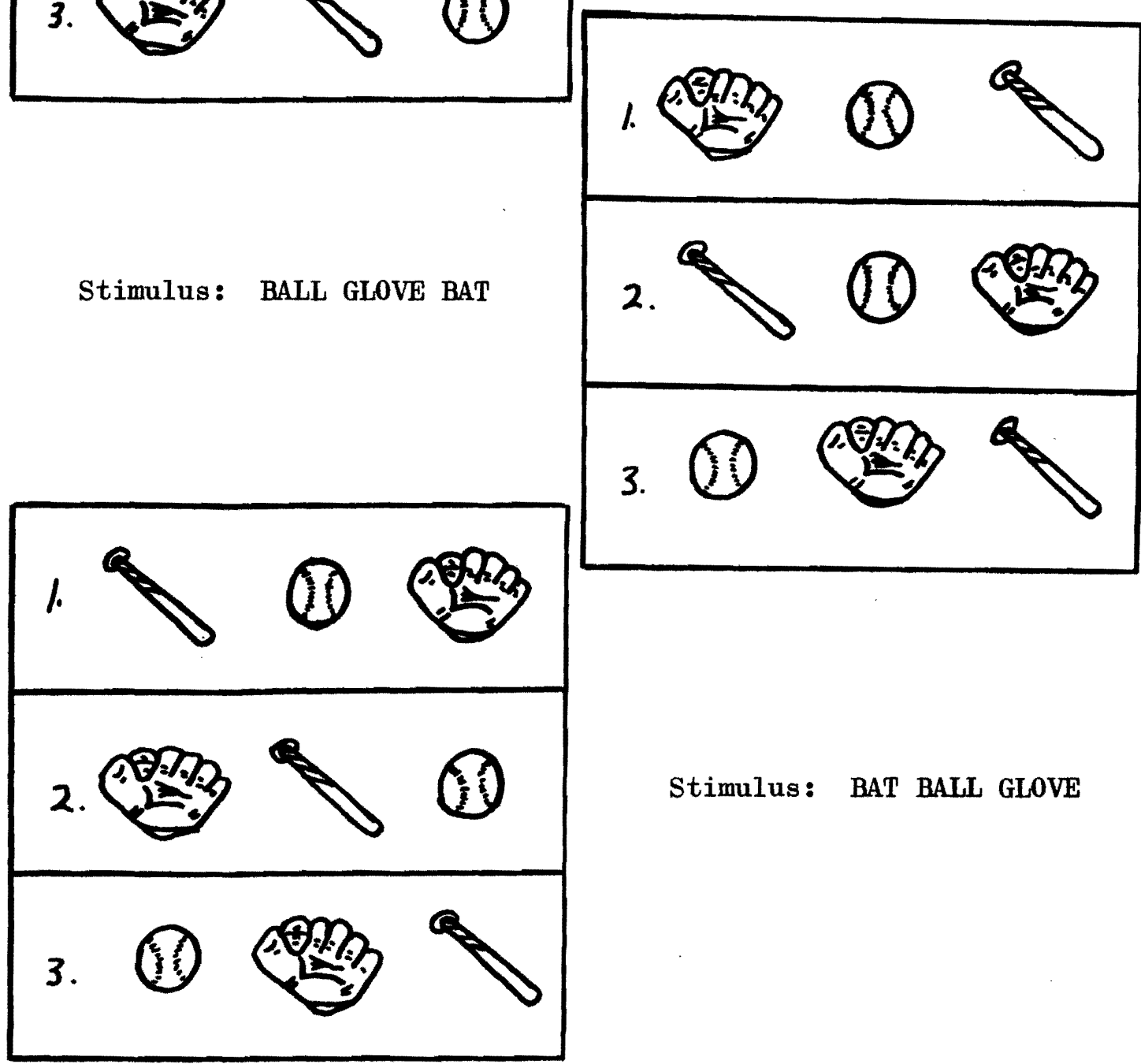

Stimulus: BAT BALL GLOVE

Figure 3. Example of three word picture sequences. 
presented individually by the experimenter who placed the card in the ECR unit, allowed the subject to visually scan the pictures on the card, and depressed the playback button of the ECR unit causing the playback head to move across the tape and activate the auditory stimulus. Order of experimental task presentation was randomized for each subject, and subjects were given a ten-minute rest period between the second and third tasks.

Subjects were trained individually prior to administration of each task. Three stimulus cards (containing pictures other than those used in the actual experimental tasks) were used for training on each task. Subjects were given instruction, and if necessary, demonstration until training was accomplished. Subjects who were unable to demonstrate that they understood how to respond to the tasks were excluded from the study.

\section{Stimulus Selection}

Experimental task stimuli (pictures) were selected on the basis of 50 normal adults' responses to a 195-item word association task. These 195 words (Appendix A) were all picturable nouns selected from the 3,000 most frequently used English words (Thorndike and Lorge, 1964). The 50 normal adults were instructed to write beside each of the 195 words the noun they most commonly associated with that word. Based on the frequency of their responses to the 195 words, 15 words and the two most frequently occurring picturable noun responses to them were selected as stimuli for the experimental tasks. Five of these words and their responses were designated as having a high degree of 
semantic associational strength (high SAS), five a moderate degree of semantic associational strength (moderate SAS), and five low semantic associational strength (low SAS) (Table II). For the high SAS stimuli, the two words most frequently elicited from the original stimulus words comprised at least 70 percent of all responses. For the moderate SAS stimuli, the two words most frequently evoked in response to the original stimulus word comprised at least 18 but not more than 46 percent of all responses. Low SAS stimuli were composed of words (selected by the experimenter) that were never given in response to the original stimulus word.

High SAS, moderate SAS, and low SAS stimuli were randomized within each of the three experimental tasks. Appendices B, C, and D show the stimulus order for experimental tasks 1, 2, and 3, respectively.

\section{Scoring of Responses}

Subject's responses to each task stimulus were scored with a modified multidimensional scoring system similar to the 16 point system described by Porch (1971). Scores for the multidimensional system were: 5 for an accurate, responsive, prompt response; 4 for an accurate, delayed response; 3 for a self-corrected response; 2 for an accurate response with one repeat; 1 for an accurate response with two repeats; and 0 for an error. Criteria for scoring judgments were:

5 CORRECT - an accurate, responsive, prompt response following stimulus presentation.

4 DELAY - an accurate response made with hesitation, after significant time lapse or any verbalizations from the subject to assist in stimulus recognition. 
TABLE II

STIMULI SELECTED FOR THE

EXPERIMENTAL TASKS

\begin{tabular}{|c|c|c|c|}
\hline $\begin{array}{l}\text { Original High SAS } \\
\text { Stimulus Word }\end{array}$ & \multicolumn{2}{|c|}{$\begin{array}{l}\text { Frequency of Response } \\
\text { Occurrence }\end{array}$} & $\begin{array}{l}\text { Combined Percent } \\
\text { of Total }\end{array}$ \\
\hline $\mathrm{BOY}$ & GIRL(43) & $\operatorname{MAN}(3)$ & $92 \%$ \\
\hline BAT & BALL (42) & GLOVE(3) & $90 \%$ \\
\hline FORK & $\operatorname{KNIFE}(30)$ & SPOON(15) & $90 \%$ \\
\hline TOE & FOOT(35) & FINGER(4) & $78 \%$ \\
\hline TABLE & CHAIR(31) & $\operatorname{DESK}(5)$ & $72 \%$ \\
\hline
\end{tabular}

\begin{tabular}{|c|l|c|}
\hline $\begin{array}{l}\text { Original Moderate } \\
\text { SAS Stimulus Word }\end{array}$ & $\begin{array}{l}\text { Frequency of Response } \\
\text { 0ccurrence }\end{array}$ & $\begin{array}{l}\text { Combined Percent } \\
\text { of Total }\end{array}$ \\
\hline SHIRT & PANTS(14) TIE(9) & $46 \%$ \\
DOOR & WINDOW(13) $\operatorname{HOUSE}(8)$ & $42 \%$ \\
APPLE & ORANGE(8) PEAR(6) & $28 \%$ \\
BED & $\operatorname{BLANKET(8)} \operatorname{PILLOW(5)}$ & $26 \%$ \\
CAR & TRUCK(6) $\operatorname{BUS}(3)$ & $18 \%$ \\
\hline
\end{tabular}

\begin{tabular}{|c|ll|c|}
\hline $\begin{array}{l}\text { Original Low SAS } \\
\text { Stimulus Word }\end{array}$ & $\begin{array}{l}\text { Frequency of Response } \\
\text { 0ccurrence }\end{array}$ & $\begin{array}{l}\text { Combined Percent } \\
\text { of Total }\end{array}$ \\
\hline GLASS & $\operatorname{SHOE}(0)$ & $\operatorname{MOON}(0)$ & - \\
COW & $\operatorname{TREE}(0)$ & $\operatorname{BRUSH}(0)$ & - \\
BOAT & $\operatorname{STAR}(0)$ & $\operatorname{KING}(0)$ & - \\
CUP & $\operatorname{BOOK}(0)$ & $\operatorname{DOG}(0)$ & - \\
HAT & $\operatorname{PEN}(0)$ & $\operatorname{EGG}(0)$ & - \\
\hline
\end{tabular}


3 SELF-CORRECTION - an accurate response correcting a previously committed response that was in error.

2 REPEAT \# 1 - an accurate response made after one repetition of the stimulus, when requested by the subject.

1 REPEAT \# 2 - an accurate response made after two repetitions of the stimulus, when requested by the subject.

0 ERROR - an incorrect response or no response.

Scorer Reliability

To determine interscorer reliability, nine of the subjects were administered the experimental tasks with the experimenter and one trained observer scoring simultaneously. The additional scorer sat behind and to the left of the subject, with an adequate view of the stimulus cards. Scoring reliability was measured as the percentage of agreement between the experimenter and the scoring observer. 
CHAPTER IV

RESULTS AND DISCUSSION

\section{RESULTS}

\section{Performance of Normal Control Subjects}

The 12 normal control subjects exhibited no difficulties whatsoever with the three experimental tasks. All responses given by normal subjects were accurate, responsive, and prompt and received scores of 5 on the modified multidimensional scoring system. For this reason no comparisons of the performance of controls and aphasics were attempted since such comparisons would be meaningless in light of the relative simplicity of the three auditory tasks for the normal group.

\section{Interscorer Reliability}

of the aphasic group 1215 individual responses (135 from each of 9 subjects) were simultaneously scored by the experimenter and the scoring observer. Using the $0-5$ point modified multidimensional scoring system the experimenter and the scoring observer achieved perfect agreement on $94.5 \%$ of all responses scored. The overall interscorer correlation for the experimenter and the observer was .995 . On the $5.5 \%$ of the responses on which the experimenter and observer disagreed, the majority $(5.1 \%)$ involved disagreement between a 4 (delayed) and a 5 (correct) response. Only .4\% of the responses did not involve 
a 4 - 5 judgment, and disagreement was greater than one number for only $.16 \%$ of all responses scored.

\section{Effects of SAS upon Auditory Comprehension}

One of the primary questions raised for this study was whether the degree of semantic associational strength (SAS) between words would influence aphasic subjects' comprehension. Group means ( $N=28)$ for the aphasic subjects plotted in Figure 4 show that aphasics have substantially more difficulty auditorily selecting a picture sequence of high SAS words than a sequence of moderate SAS or low SAS words, and more difficulty selecting a picture sequence of moderate SAS words than a sequence of low SAS words. Group means for the low, moderate, and high SAS stimuli (Figure 4) were 4.49, 4.07, and 3.71 respectively (F=29.23; $d f=2,54 ; p .001)$ suggest that the higher the degree of SAS between words the more adversely aphasics' comprehension will be influenced.

Effects of Sequence Length upon Auditory Retention

A second question asked in this investigation dealt with the effects of message length upon aphasic subjects' auditory retention ability. In this light results are highly supportive of previous investigations that show aphasics' retention ability to be adversely influenced by an increase in message length (Filby et al., 1963; Schuell et al., 1965; Shewan and Cantor, 1971). Figure 5 shows that the aphasic groups' means $(\mathrm{N}=28)$ for one, two, and three word sequences, irrespective of degree of SAS between words of a sequence, were 4.56, 3.92, and 3.79 respectively $(F=33.52 ; \mathrm{df}=2,54 ; \mathrm{p} .001)$. These data suggest that aphasics have relatively little difficulty retaining 


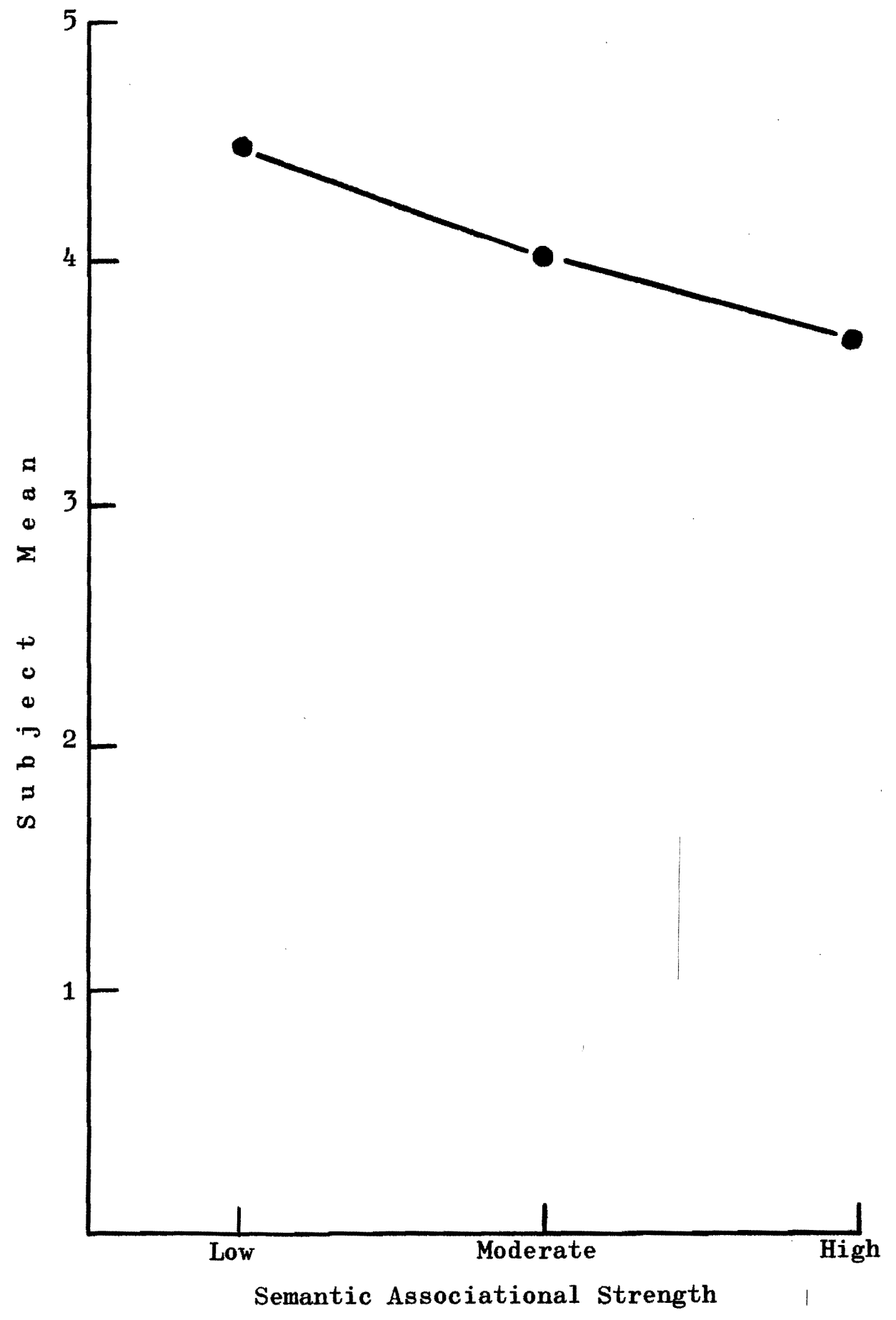

Figure 4. Aphasic subjects' means for low, moderate, and high SAS stimuli. 


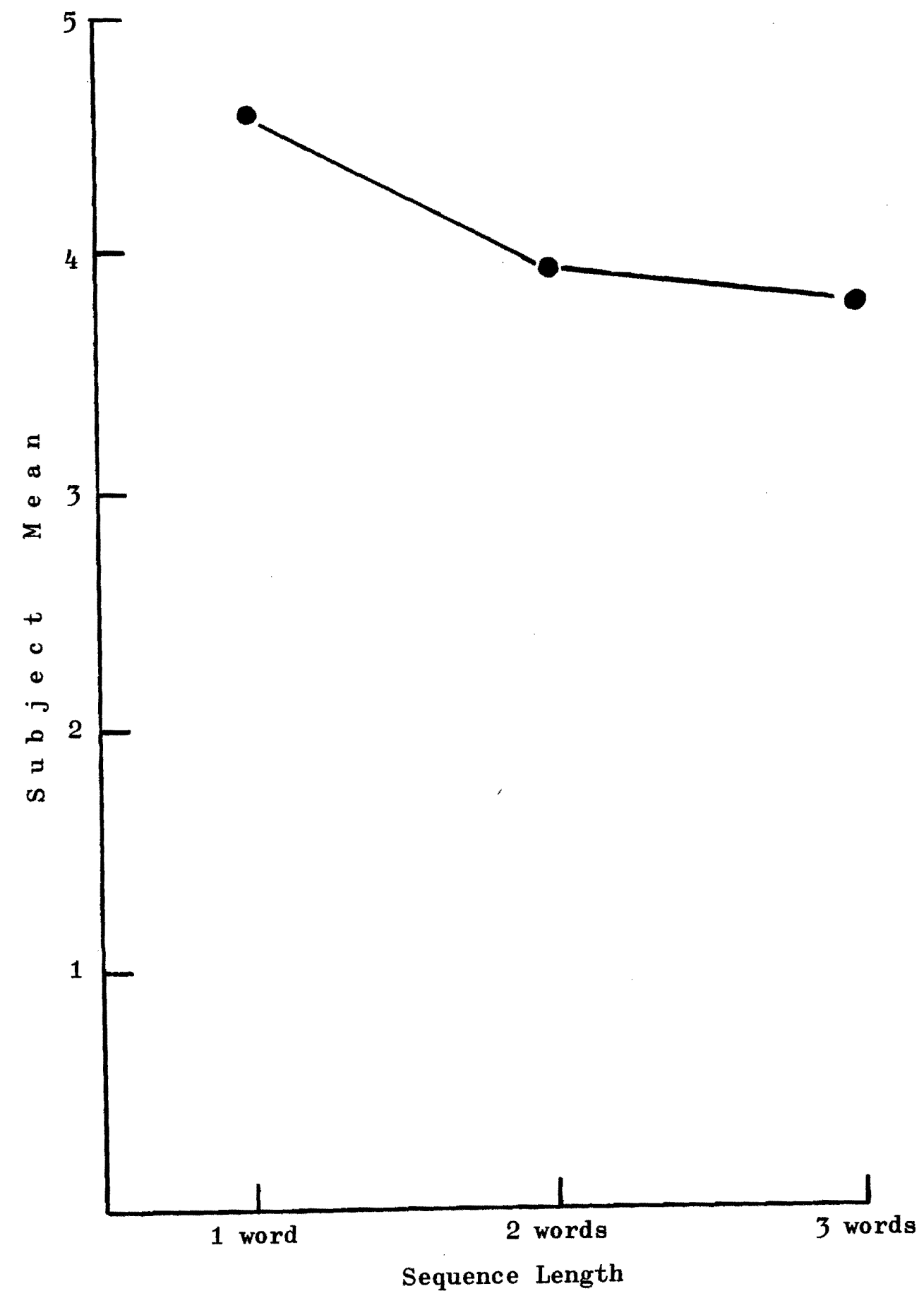

Figure 5. Aphasic subjects' means for one, two, and three word verbal sequences. 
single words; their retentional ability for two and three word sequences, however, is substantially below that for single words and they have almost as much difficulty remembering two word sequences as they do three word sequences.

Effects of SAS upon Auditory Retention of One, Two, and Three Word Sequences

A third question asked in the study centered on the differential effects of degree of SAS upon aphasics' ability to retain one, two, and three word sequences. Figure 6 shows aphasic subjects' means for high, moderate, and low SAS stimuli at each of the three verbal sequence lengths. To determine whether a significant interaction existed between the factors of SAS and sequence length a $3 \times 3$ factorial analysis of variance was applied to the data. Visual observation of the data in Figure 6 clearly points out the existence of a significant interaction between the SAS and length factors $(F=5.0769 ; \mathrm{df}=2,54$; p .001). Further inspection of Figure 6, however, suggests that this interaction was primarily the result of subjects' performance on the moderate SAS stimuli. Surprisingly, subjects performed differently in terms of their ability to retain moderate SAS than high or low SAS sequences. While they had relatively little difficulty retaining moderate SAS single word sequences, they illustrated an inordinate decrement in their ability to retain moderate SAS two word sequences. Figure 6 illustrates that the aphasic subjects in this study performed approximately the same on the moderate SAS two word sequences as the 


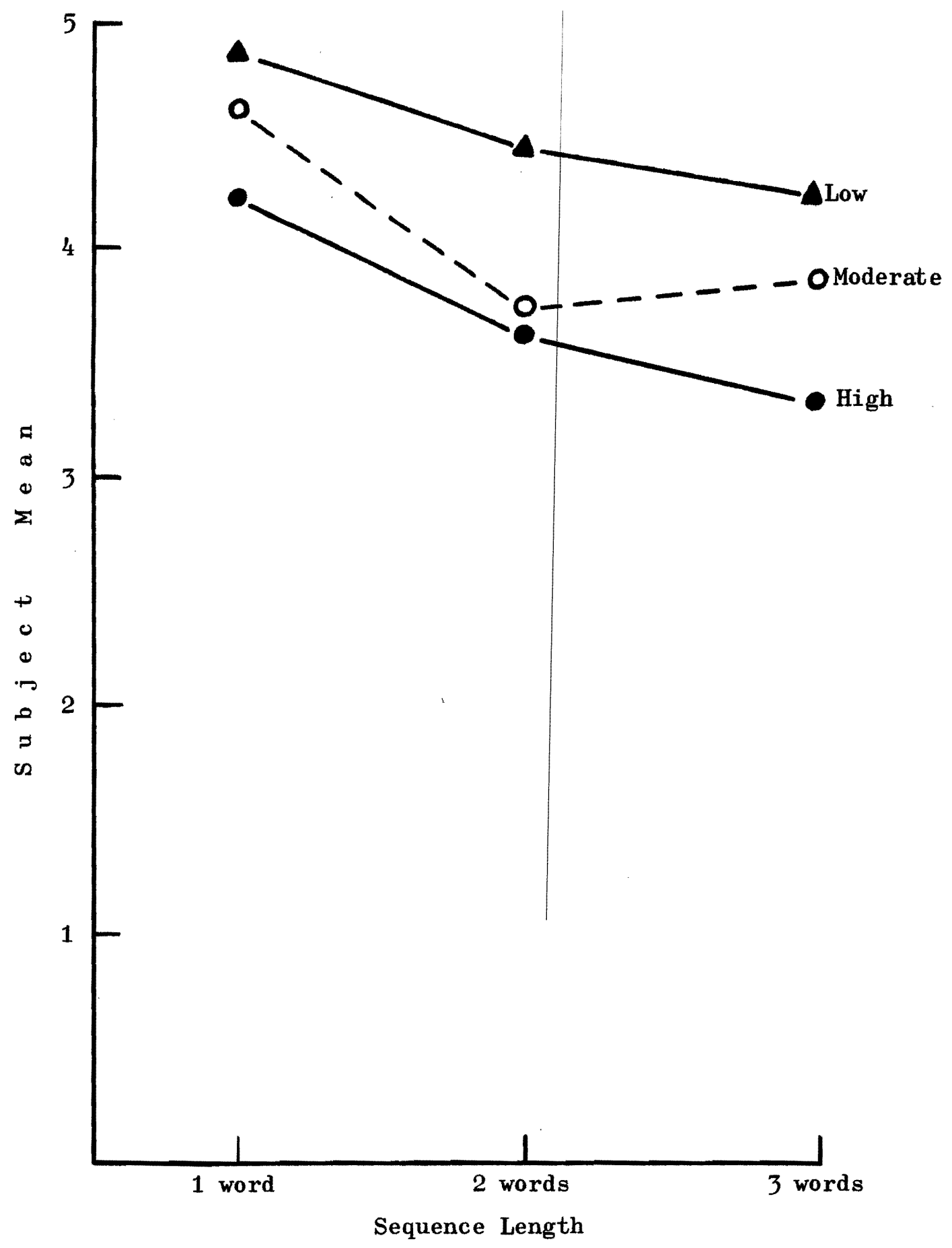

Figure 6. Aphasic subjects' means for low, moderate, and high SAS stimuli at three verbal sequence lengths. 
high SAS two word sequences, and in fact had a slightly lower group mean for the moderate SAS two word sequences than the moderate SAS three word sequences.

Relationship of Auditory Comprehension and 0verall Language Ability

Figure 7 shows individual subject's overall means for the three auditory tasks plotted against their overall percentile scores for the PICA. It can be seen that subjects' overall rankings on the PICA ranged from the 37 th to the 95 th percentiles, while grand means for the auditory tasks ranged from 2.97 to 4.92. The clustering of the data points in Figure 7 along the plotted regression line suggests a high positive correlation between the auditory comprehension variables explored in this study and overall communicative ability. The correlation between subjects' auditory comprehension performance and overall communicative ability (measured by the PICA) was .793. This would appear to support earlier studies of Schuell et al. (1965) and Smith (1971) that the auditory comprehension ability in aphasics is generally reflective of the person's overall language ability.

\section{DISCUSSION}

The findings of this investigation substantiate results of previous studies that have shown aphasics to have difficulty comprehending the meaning of words (DeRenzi and Vignolo, 1962; Spinnler and Vignolo, 1966; Pizzamiglio, 1971) and to confuse words that are semantically related (Schuell and Jenkins, 1961). Unlike previous studies dealing with the auditory comprehension of aphasic adults, however, this study 


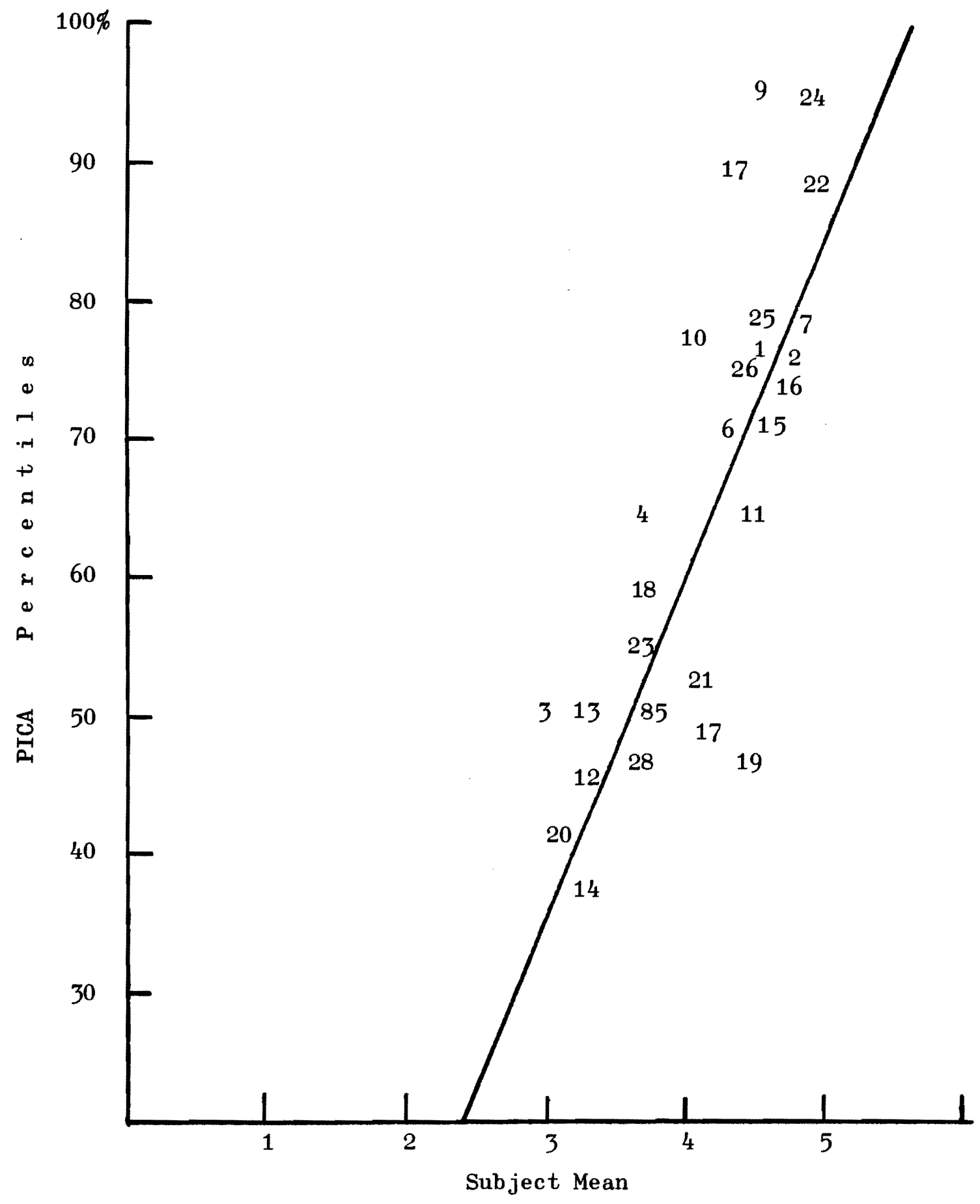

Figure 7. Regression line for aphasic subjects' grand means for the auditory tasks and overall PICA percentiles. 
attempted to determine the degree of semantic associational strength (SAS) between words presented auditorily to aphasic patients. Results indicate that the stronger the semantic relationship between words the more adversely aphasics' comprehension will be affected. Aphasic subjects in this study (Figure 4) had substantially more difficulty selecting sequences of high SAS words than selecting sequences of moderate SAS and low SAS words and considerably more difficulty selecting sequences of moderate SAS words than sequences of low SAS words. It would appear therefore, as Schuell et al. $(1961,1965)$ and others (Luria, 1970) have suggested, that in aphasia the associational processes break down and this impairment adversely influences comprehensional ability. The fact that aphasic subjects in this study showed a decrease in comprehensional ability as relatedness (SAS) between word stimuli increased suggests that it may be possible to construct an associational hierarchy for aphasics and that a given patient's level of comprehension or ranking on this hierarchy may possibly be related to his overall level of linguistic functioning.

This study also differed methodologically from previous investigations in that an attempt was made to limit the vocabulary level of the words presented to the aphasic group. Schuell and Jenkins (1961) for example, presented subjects four pictures, "the stimulus word (chair)," "a phonetically similar word (stair)," "a semantically related word (table)," and "an unrelated word (apple)." Spinnler and Vignolo (1966) had aphasic subjects select one of four pictures associated with a sound presented auditorily and Pizzamiglio (1971) used as stimuli four words having a high degree of associational overlap from 
Italian word association norms. This study used word stimuli (based on 50 normal individuals' two most frequently elicited associational

responses) from the 3,000 most frequently used English words (Thorndike and Lorge, 1964). There is some reason to believe that it may be advantageous to control for vocabulary level when studying the influence of semantic association on aphasics' comprehension. First, it has been shown that aphasics retain and use words that are concrete, functional, and short (Wepman et al., 1956; Filby et al., 1963). At the same time, Keenan (1968) has pointed out that aphasics recognize words far more easily than they recall them. Inasmuch as most procedures used to assess aphasics' auditory comprehension are recognition type tasks it is probably important to increase the probability that the aphasic will recognize the words presented. If stimuli are not selected from a vocabulary that heightens the probability of the aphasic recognizing them then one cannot be sure if an impaired performance is related to lack of recognition or associational confusion. The difficulty exhibited by aphasic subjects of this study in comprehending the concrete noun words used as stimuli indicates, however, that associational processes probably suffer impairment at all levels of complexity in aphasia. Several investigators have shown aphasics to be impaired in terms of verbal retention span (Filby et al., 1963; Schuell et al., 1965; Shewan and Cantor, 1971) and the fact that aphasic subjects in this study had substantially more difficulty retaining longer word sequences is not surprising. It is interesting however, (Figure 5) that aphasic subjects had almost as much difficulty retaining two word sequences as they did three word sequences. While subjects had little difficulty 
with one word sequences, there is reason to believe that increasing sequence length by one word is sufficient to markedly overtax the retentional ability of many aphasics. It is also possible that having the aphasic remember a sequence of words is more likely to identify a retentional problem than having him follow a direction, in that the latter task provides more redundancy than the former. Aphasic adults may in fact appear to retain more redundant messages quite well but display marked difficulty with non-redundant stimuli such as digits and word sequences. This has been shown in several studies using the Token Test (DeRenzi and Vignolo, 1962; Boller and Vignolo, 1966; Orgass and Poeck, 1966; Spellancy and Spreen, 1969). In these studies aphasics having no readily apparent comprehension problems for connected speech have exhibited performances which were markedly inferior to normal subjects on the minimally redundant Token Test.

An interaction hypothesis involving the SAS and sequence length factors would postulate that the greater the degree of SAS between words the more adversely would aphasics' retention be affected by an increase in message length. In this instance the amount of slope of each line connecting aphasic group means (Figure 6) for high, moderate, and low SAS stimuli at each sequence length is indicative of SAS effects as auditory load increases. To support an interaction hypothesis one would expect the most pronounced slope for the high SAS line and the least pronounced slope for the low SAS line, with the moderate SAS line falling in between. Figure 6 shows, however, the existence of a significant interaction between the SAS and length factors, primarily on the basis of subjects' performances on the moderate SAS two word 
sequences. This unfortunately negated the support for the interaction hypothesis reflected in the slopes of the high and low SAS lines.

The surprising performance of the aphasic group on the moderate SAS stimuli may have been due to the manner in which these stimuli were selected. Table II shows high, moderate, and low SAS stimuli selected on the basis of fifty normal individuals' word association responses. It can be seen that the two most frequent associational responses to stimulus words in the moderate SAS group occurred with almost equal frequency in many instances. Conversely, the two most frequent associational responses to words selected as high SAS stimuli illustrated a marked preference for one specific word. Luria (1972) has hypothesized that alteration in the aphasic's neurodynamic regulatory mechanism may result in an unselective organization of associations such that all possible associations have an equal probability of being selected. In other words, an incoming stimulus excites an associational matrix from which the individual must select a response. It seems reasonable that the more extensive this matrix the more difficult it will be for the aphasic to select an appropriate response. It is possible that this is what occurs with the moderate SAS stimuli in that more associational responses might be expected to occur to words like "shirt" and "bed" (moderate SAS) than words like "boy" and "bat" (high SAS) which seem to generate a limited number of words as associations.

Aphasics' performance on the three experimental tasks of this study was highly related to their overall communicative ability as assessed by the PICA. This finding is highly supportive of previous studies by Schuell et al. (1965) and Smith (1971) which suggest that a 
patient's comprehension deficit is a good indication of his overall language impairment. As can be seen in Table $I$, the aphasics in this study illustrated a wide range of communicative ability as reflected in their PICA percentiles. The fact that no aphasic subject had a grand mean (Figure 7) of more than 4.92, whereas all normal controls had a grand mean of 5.00 (no errors) indicates that impairment of the auditory processes is present even with the mildest forms of aphasia. This would seem to support the contention that aphasia is a language disturbance that is reflected in all language modalities (Schuell et al., 1965). It should also be pointed out that many of the subjects who had higher overall means for the three auditory tasks (Figure 7 - numbers $7,16,22,24)$ displayed only mild aphasic characteristics but were primarily impaired in the ability to communicate because of a concomitant apraxia and/or dysarthria. This would again seem to confirm the point of view of Schuell et al. (1965) that aphasia is a language disturbance that may or may not be complicated by other sequalae of brain damage. 


\section{CHAPTER V}

\section{SUMMARY AND CLINICAL IMPLICATIONS}

\section{SUMMARY}

The purpose of this study was to investigate the effects of semantic associational strength (SAS) upon adult aphasics' auditory comprehension abilities. Twenty-eight adult aphasics (25 males and 3 females) and 12 adult normal control subjects were presented three experimental tasks, each containing 45 items. Experimental task 1 contained single word picture sets of high SAS, moderate SAS, and low SAS words. Experimental task 2 contained two word picture sets of high, moderate, and low SAS words and experimental task 3 similarly contained three word picture sets of high, moderate, and low SAS words. Subjects heard one, two, and three word verbal sequences for experimental tasks 1, 2, and 3, respectively, and pointed to the appropriate picture sequence. Level of SAS was determined on the basis of the two most frequently occurring word associations of 50 normal individuals to 195 words from the most frequently occurring 3,000 English words (Thorndike and Lorge, 1964).

Similar to the findings of Schuell and Jenkins (1961) and Pizzamiglio (1971) results of this study suggest aphasics will confuse semantically related words. Results also suggest, however, that the higher the degree of word relatedness (SAS) the more adversely aphasics' comprehension will be influenced. In this study aphasics had 
substantially more difficulty auditorily selecting picture sequences of high SAS words than sequences of moderate and low SAS words and more difficulty selecting sequences of moderate SAS words than sequences of low SAS words.

Results of this study also parallel those of others (Filby et al., 1963; Schuell et al., 1965; Shewan and Cantor, 1971) who have clearly shown that as length is increased the more difficulty aphasics have retaining what they hear. Findings indicated that increasing sequence length by one word may be sufficient to markedly impair many aphasics' retentional abilities.

It was also hypothesized that degree of SAS would differentially affect aphasics comprehension as message length increased. While the SAS factor had relatively little influence on subjects' ability to retain low SAS stimuli and a rather profound influence on aphasics' retention of high SAS stimuli, subjects' performance on the moderate SAS two word sequences paralleled that for high SAS two word sequences. This resulted in a significant interaction between the SAS and length factors and negated the support for an interaction hypothesis.

The high positive correlation between the experimental task and PICA measurement of overall communicative ability strongly supports Smith's (1971) report that the severity of the patients' comprehension deficit reflects the overall language impairment. These findings further reinforce the notion of Schuell et al. (1965) that aphasia is a general language deficit with impairment reflected across all language modalities. 


\section{CLINICAL IMPLICATIONS}

Clinically, the findings of this study seem to support the contention of Schuell et al. (1965) that the speech clinician working with aphasics employ a highly auditory treatment approach based on intensive, repetitive auditory stimulation. Results further imply that the aphasia clinician can manipulate word relatedness, verbal sequence length, and message redundancy of stimulus presentations to facilitate programing treatment that is commensurate with each patient's level of performance.

Use of the modified $0-5$ point multidimensional scoring system provided results that described the nature of each subject's responses in considerable detail. If appropriate stimuli are being presented, more 5 (correct) and 4 (delayed) responses, rather than 3 (selfcorrected) or $2-1$ (stimulus repetition) responses should be elicited from the aphasic. Incorporation of this type of system would enable the clinician to distinguish the accuracy, responsiveness, and promptness of all responses and could be of value in programing treatment and evaluation of aphasic's level of performance. 


\section{REFERENCES}

Barry, M. F., and Eisenson, J., Speech Correction: Principles and Methods. New York: Appleton-Century-Crofts, Inc. (1956).

Boller, F., and Green, E., Comprehension in severe aphasics. Cortex, 8, No. 4, 382-394 (1972).

Boller, F., and Vignolo, L. A., Latent sensory aphasic in hemispheredamaged patients: an experimental study with the token test. Brain, 89, 815-830 (1966).

Brookshire, R. H., Differences in auditory processing deficits among aphasic patients. 1972 ASHA Convention, San Francisco, California (1972).

Carpenter, R. L., and Rutherford, D. R., Acoustic cue discrimination in adult aphasia. J. Speech Hearing Res., 16, No. 3, 534-544 (1973).

Cohen, J. G., and Edwards, A. E., Word length and discrimination behavior of aphasics. J. Speech Hearing Res., 7, 343-348 (1964).

Cramer, P., Word Association. New York and London: Academic Press (1968).

DeRenzi, E., and Vignolo, L. A., The token test: a sensitive test to detect receptive disturbances in aphasia. Brain, 85, 65-78 (1962).

Ebbin, J. B., and Edwards, A. E., Speech sound discrimination of aphasics when intersound interval is varied. J. Speech Hearing Res., 10, No. 1, 120-125 (1967).

Eisenson, J., Examining for Aphasia. New York: The Psychological Corp. (1954).

Filby, Y., Edwards, A. E., and Seacat, G. F., Word length, frequency and similarity in discrimination behavior of aphasics. J.Speech Hearing Res., 6, No. 3, 255-263 (1963).

Geschwind, N., The language of the brain. Scientific Amer., 226, $76-83$ (1972).

Keenan, J. S., The nature of receptive and expressive impairments in aphasia. J. Speech Hearing Dis., 33, No. 1, 20-25 (1968). 
Luria, A. R., Brain disorders and language analysis. Language and Speech, 1, 14-34 (1958).

Luria, A. R., Traumatic Aphasia: Its Syndromes, Psychology and Treatment. Mauton: The Hauge Press (1970).

Luria, A. R., Aphasia reconsidered. Cortex, 8, 34-40 (1972).

McMahon, L., Grammatical analysis as part of understanding a sentence. Unpublished Ph. D. Dissertation, Harvard University (1963).

Nichols, J. L., Effects of three aspects of sentence structure on immediate recall. Speech Monographs, 32, 164-168 (1965).

Orgass, B., and Poeck, K., Clinical validation of a new test for aphasia: an experimental study on the token test. Cortex, 2, 222-243 (1966).

0sgood, C. E., and Murray, M., Approaches to the Study of Aphasia. Urbana: University of Illinois Press (1963).

Parisi, P., and Pizzamiglio, L., Syntactic comprehension in aphasia. Cortex, 6, 204-215 (1970).

Perry, P., and Boswell, N., The use of local norms in the study of adult aphasic vocabulary comprehension. 1971 ASHA Convention, Chicago, Illinois (1971).

Pizzamiglio, L., Semantic comprehension in aphasia. J. Commun. Dis., 3, 280-288 (1971).

Porch, B. E., Porch Index of Communicative Ability: Administration, Scoring, and Interpretation. Palo Alto, California: Consulting Psychologists Press (1967).

Porch, B. E., Multidimensional scoring in aphasia testing. J. Speech Hearing Res., 14, No. 4, 776-792 (1971).

Rinnert, C., and Whitaker, A. W., Semantic confusions by aphasic patients. Cortex, 9, No. 1, 56-81 (1973).

Savin, H. B., Word frequency effect and errors in the perception of speech. J.Acoustic Soc. Amer., 35, 200-206 (1963).

Schue11, H. M., Auditory impairment in aphasia: significance and retraining techniques. J. Speech Hearing Dis., 18, 14-21 (1953).

Schuell, H. M., and Jenkins, J. J., Reduction of vocabulary in aphasia. Brain, 84, 243-261 (1961). 
Schuel1, H. M., Jenkins, J. J., and Carroll, J. B., A factor analysis of the Minnesota test for differential diagnosis of aphasia. J. Speech Hearing Res., 5, 349-369 (1962).

Schue11, H. M., Jenkins, J. J., and Jinenex-Pabon, E., Aphasia in Adults: Diagnosis, Prognosis and Treatment. New York and London: Hoeber Medical Division, Harper and Row, Pub. (1965).

Schue11, H. M., Jenkins, J. J., and Landis, L., Relationship between auditory comprehension and word frequency in aphasics. J. Speech Hearing Res., 4, 30-36 (1961).

Sefer, J., and Henrikson, E. H., The relationship between word association and grammatical class in aphasia. J. Speech Hearing Res., 9, No. 4, 529-541 (1966).

Shewan, C., and Cantor, G., Effects of vocabulary, syntax and sentence length on auditory comprehension in aphasic patients. Cortex, 7, 209-226 (1971).

Smith, A., Objective indices of severity of chronic aphasia in stroke patients. J. Speech Hearing Dis., 37, 155-176 (1971).

Spellacy, F. J., and Spreen, 0., A short form of the token test. Cortex, 5, 390-397 (1969).

Spinnler, J., and Vignolo, L. A., Impaired recognition of meaningful sounds in aphasia. Cortex, 2, 337-348 (1966).

Spreen, 0., and Benton, A. L., Neurosensory Center Comprehensive Examination for Aphasia. University of Victoria: Neuropsychology Laboratory Department of Psychology (1969).

Swinney, D. A., and Taylor, Short-term memory recognition search in aphasics. J. Speech Hearing Res., 14, 578-588 (1971).

Taylor, M. L., The Functional Communication Profile Manual of Directions. New York University Medical Center: Institute of Rehabilitation Medicine (1969).

Thorndike, E. L., and Lorge, The Teacher's Word Book of 30,000 Words. New York: Columbia Press (1964).

Tikofsky, R. S., Two studies of verbal learning by adult aphasics. Cortex, 7, 106-125 (1971).

Van Riper, C., Speech Correction: Principles and Methods. Fnglewood Cliffs, New Jersey: Prentice-Hall, Inc. (1963). 
Vignolo, L. A., Evolution of aphasia and language rehabilitation: a retrospective exploratory study. Cortex, 1, 344-367 (1964).

von Stockert, T. R., Recognition of syntactic structure in aphasic patients. Cortex, 8, No. 3, 323-334 (1972).

Wei senburg, T. H., and McBride, K. E., Aphasia. New York: Commonwealth Fund (1935).

Wepman, J. M., Recovery from Aphasia. New York: The Ronald Press Co. $(1951)$.

Wepman, J. M., and Jones, L. V., The Language Modalities Test for Aphasia. Chicago, Illinois: Education Industry Service (1961).

Wepman, J. M., Jones, L. V., Bock, R. D., and Van Pelt, D., Studies in aphasia: background and theoretical formulations. J. Speech Hearing Dis., 25, 323-332 (1960).

Wepman, J. M., Jones, L. V., Van Pelt, D., and Bock, D. R., Psycholinguistic study of aphasia: a revision of the concept of anomia. J. Speech Hearing Dis., 21, No. 4, 468-477 (1956).

Wiig, E. H., and Globus, D., Aphasic word identification as a function of logical relationship and association strength. J. Speech Hearing Res., 14, No. 1, 195-204 (1971). 
APPENDICES 
APPENDIX A

ASSOCIATION TASK GIVEN TO 50 NORMAL ADULTS

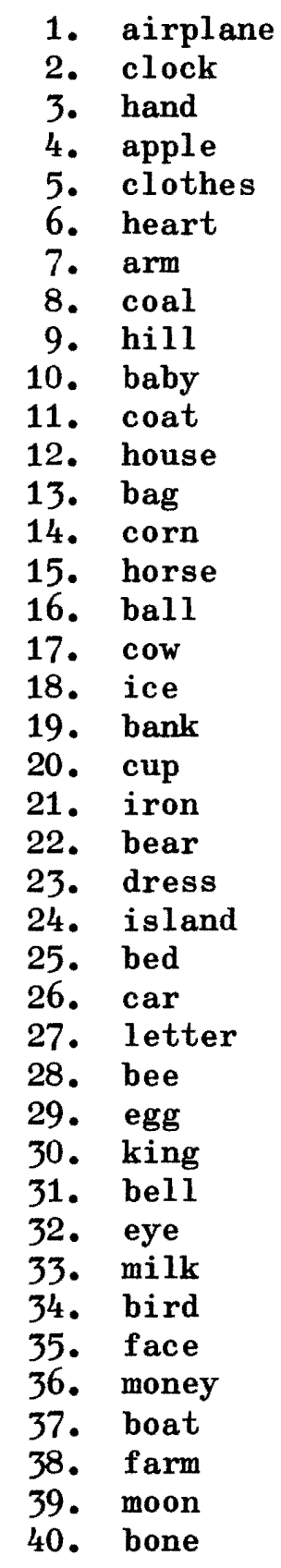

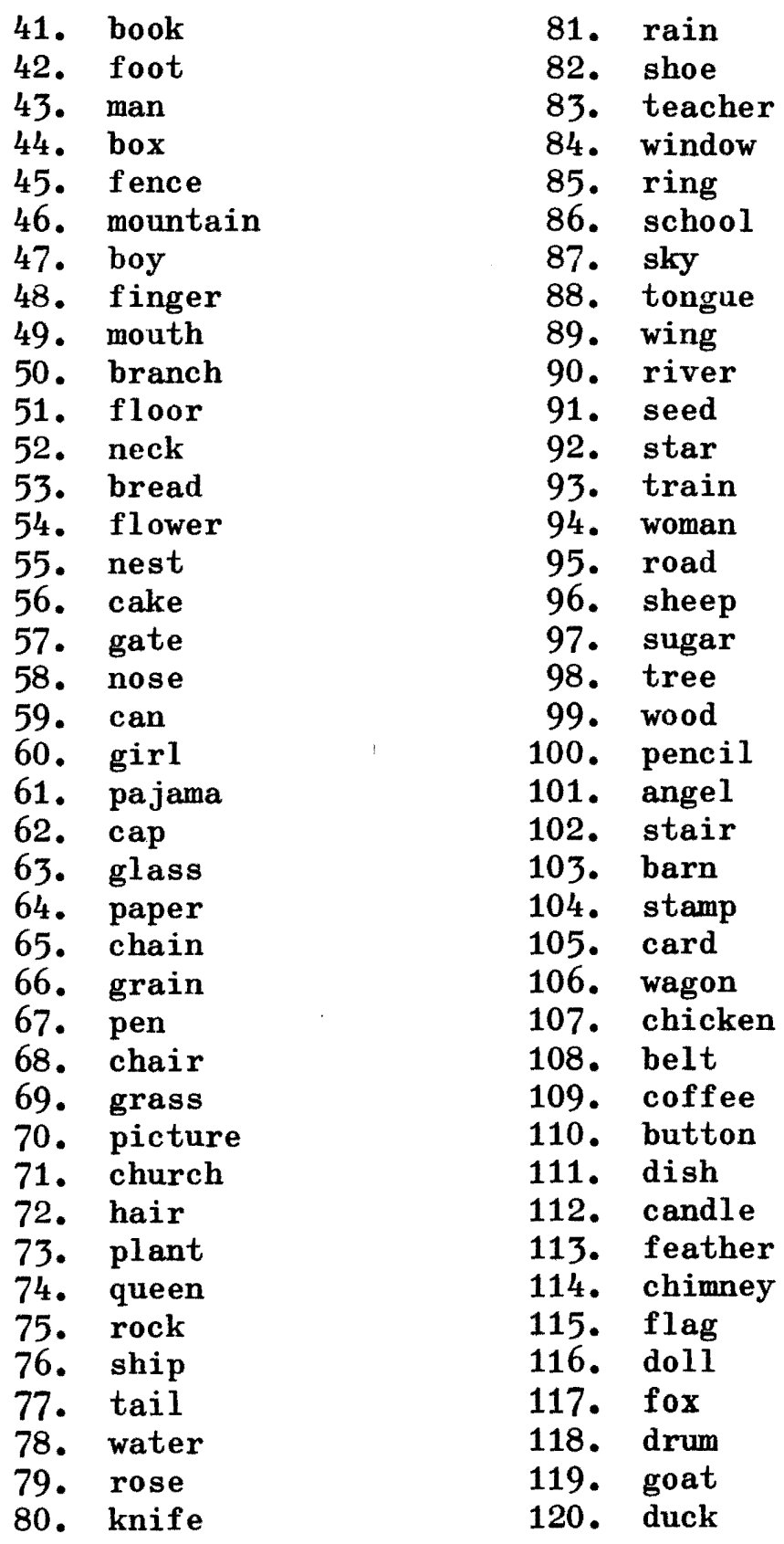


121. gun

122. goose

123. fork

124. key

125. eagle

126. glove

127. needle

128. lamp

129. mouse

130. nail

131. penny

132. nut

133. purse

134. orange

135. rabbit

136. pie

137. shirt

138. pig

139. spoon

140. pin

141. swing

142. pipe

143. tooth

144. plate

145. ribbon
146. potato

147. robe

148. frog

149. hat

150. jar

151. bus

152. kettle

153. ant

154. ladder

155. apron

156. pea

157. arrow

158. peach

159. pear

160. pillow

161. comb

162. rug

163. bandage

164. balloon

165. toe

166. bat

167. turkey

168. bike

169. vest

170. cage
171. witch

172. cane

173. barrel

174. carrot

175. bubble

176. cart

177. fish

178. dart

179. crown

180. deer

181. f an

182. ink

183. insect

184. plow

185. oven

186. pail

187. soap

188. wreath

189. door

190. desk

191. sucker

192. pitcher

193. sink

194. table

195. brush 
APPENDIX B

STIMULUS ORDER FOR EXPERIMENTAL TASK 1

Card Top

1. bat

2. star

3. fork

4. glove*

5. shoe $^{*}$

6. ball

7. spoon*

8. pen*

9. chair $^{*}$

10. $\operatorname{dog}^{*}$

11. truck

12. girl

13. cow

14. moon

15. door

16. egg

17. moon*

18. tie

19. toe

20. man

21. orange

22. man

23. tie $^{*}$

24. car* $^{*}$

25. toe*

26. knife

27. window

28. pillow*

29. hat

30. bus

31. orange*

32. house

33. table*

34. king

35. book

36. cow*

37. foot

38. table

39. tree

40. pillow
Card Middle

glove

king*

knif $e^{*}$

ball

moon

glove

knife

hat

table

cup

bus*

$\operatorname{man} *$

brush

glass*

window*

pen

shoe

pants*

foot*

girl*

pear

boy*

shirt

truck

finger

spoon

door

bed

egg*

truck*

apple

door*

desk

star

cup*

tree

toe

chair

cow

blanket
Card Bottom

ball*

boat

spoon

bat

glass

bat*

fork

egg

desk

book

car

boy

tree*

shoe

house

hat*

glass

shirt

finger

boy

apple*

girl

pants

bus

foot

fork*

house*

blanket

pen

car

pear

window

chair

boat*

$\operatorname{dog}$

brush

finger*

desk*

brush*

bed* 


41. king
42. cup
43. blanket*
44. pants
45. apple

41. king

42. cup

44. pants

45. apple boat

book*

pillow

tie

orange
star*
$\operatorname{dog}$
bed
shirt*
pear*

*Presented as Stimulus 


\section{APPENDIX C}

STIMULUS ORDER FOR EXPERIMENTAL TASK 2

Card Top

1. cow tree

2. bus truck*

3. boat king

4. tree brush

5. egg hat

6. truck car

7. table chair

8. hat pen*

9. moon shoe*

10. glove bat

11. cup book

12. shirt pants*

13. glass moon

14. boy man

15. chair desk*

16. hat egg

17. door window*

18. glass shoe

19. toe finger

20. tree brush*

21. foot toe*

22. blanket bed

23. bat ball

24. boy man*

25. car bus

26. book cup*

27. pillow bed

28. window door

29. ball bat*

30. bed blanket*

31. cup dog

32. toe foot

33. spoon knife

34. orange apple

35. desk table

36. tie shirt

37. pear orange

38. boat star*

39. tie shirt

40. house window
Card Middle

brush cow*

car bus

star boat*

cow tree

egg pen*

car bus

desk chair*

pen egg

shoe glass

bat ball*

cup $\operatorname{dog} *$

tie shirt

glass shoe*

girl boy*

desk table

egg pen

house door

moon glass

toe foot*

tree cow

finger toe

bed pillow

ball glove

man boy

truck car*

book dog

blanket bed*

house window*

ball glove

pillow bed

book cup

foot finger

knife fork

pear apple*

table chair

shirt pants

orange apple

boat king

pants tie*

door window
Card Bottom

tree brush

truck car

king star

cow brush*

pen egg

car truck*

chair desk

egg hat

glass moon

ball glove

dog book

pants tie

moon glass

man girl

table chair

pen hat*

window house

shoe moon*

foot finger

cow brush

toe finger

pillow bed*

glove bat*

boy girl

bus truck

cup book

bed blanket

house door

bat ball

blanket pillow

dog book*

finger to ${ }^{*}$

fork spoon*

apple pear

table desk*

tie pants*

apple pear*

king star

pants shirt

window door* 
41. star king

42. fork knife

43. orange apple*

44. girl boy

45. knife fork* boat star spoon fork* orange pear man girl spoon knife king boat* knife fork pear apple man boy* fork knife 


\section{APPENDIX D}

\section{STTMULUS ORDER FOR EXPERIMENTAL TASK 3}

\section{Card Top}

1. king star boat

2. tree cow brush*

3. man girl boy

4. ball bat glove

5. car bus truck*

6. tie shirt pants*

7. pillow bed blanket*

8. book dog cup

9. desk chair table

10. star boat king*

11. book cup dog

12. bus car truck

13. pillow bed blanket

14. spoon knife fork

15. moon shoe glass

16. orange pear apple*

17. man girl boy

18. window house door

19. tree cow brush

20. chair table desk

21. toe foot finger*

22. knife spoon fork

23. pen egg hat

24. pants tie shirt

25. door window house

26. orange apple pear

27. house door window*

28. king boat star

29. glove ball bat

30. pen hat egg

31. finger foot toe

32. pillow blanket bed

33. apple orange pear

34. dog cup book*

35. hat egg pen*

36. chair desk table*

37. knife fork spoon*

38. tie pants shirt

39. bus truck car

40. bat ball glove*
Card Middle

boat king star*

cow tree brush

boy girl man

glove ball bat*

car truck bus

pants tie shirt

blanket bed pillow

book cup dog*

table chair desk*

boat star king

dog cup book

car bus truck

blanket bed pillow

knife fork spoon

moon glass shoe*

pear apple orange

man boy girl*

door house window

cow tree brush

table desk chair

finger toe foot

fork knife spoon*

hat pen egg

shirt pants tie

window door house*

apple orange pear

door window house

boat king star

bat ball glove

pen egg hat*

finger toe foot*

bed pillow blanket*

apple pear orange*

book dog cup

egg hat pen

desk table chair

fork spoon knife

shirt pants tie*

truck bus car*

glove bat ball
Card Bottom

star boat king

brush cow tree

girl boy man*

glove bat ball

bus car truck

tie pants shirt

bed blanket pillow

cup dog book

chair table desk

king star boat

cup book dog*

bus truck car*

blanket bed pillow*

spoon fork knife*

shoe moon glass

apple orange pear

boy girl man

door window house*

brush tree cow*

desk chair table*

foot toe finger

spoon knife fork

egg pen hat*

pants shirt tie*

house window door

pear orange apple*

window door house

king star boat*

ball glove bat*

egg pen hat

toe foot finger

blanket pillow bed

pear orange apple

cup dog book

hat pen egg

chair table desk

spoon fork knife

pants shirt tie

car truck bus

ball glove bat 
41. foot toe finger

42. girl boy man*

43. moon shoe glass

44. cow tree brush

45. shoe glass moon* toe finger foot girl man boy glass shoe moon cow brush tree* moon shoe glass foot finger toe* boy girl man glass moon shoe* brush tree cow glass moon shoe

*Presented as Stimulus 